Chapter 4

\title{
Role of Dopaminergic and Noradrenergic Systems as Potential Biomarkers in ADHD Diagnosis and Treatment
}

\author{
Catia Scassellati and Cristian Bonvicini \\ Additional information is available at the end of the chapter \\ http://dx.doi.org/10.5772/60860
}

\begin{abstract}
This chapter aims to identify, among the dopaminergic and noradrenergic molecules strongly associated to aetiopathogenesis of the disorder, potential genetic and biochemical markers linked to ADHD diagnosis and to assess whether treatments can change peripheral levels of a biomarker, to be then useful, if tested, as a response predictor.

The results, based on literature research, evidenced a role of some molecules such as SLC6A3, DRD4, MHPG, MAOA, NE, SLC6A2, DBH, COMT that could represent, in this order, a hypothetical signature of genetic and biochemical markers useful for ADHD diagnosis. From this hypothetical signature, the NE metabolite MHPG resulted, after a meta-analytic approach, the main molecule whose urinary levels were influenced by the d-AMP treatment. Urinary MHPG levels were decreased after stimulants administration only in the responder patients, indicating that MHPG could be a useful predictor of the response to these drugs. This, along with the well-reported correlation between decrease in MHPG and behavioral improvements after d-AMP treatment, focuses attention on MHPG as a potential mediator of stimulant drug response, in addition to a potential useful biological marker for diagnostic assessment.
\end{abstract}

Future studies on specificity, sensitivity and replication of these findings are needed.

Keywords: dopaminergic systems, noradrenergic systems, biomarkers, ADHD, diagnosis, treatment

\section{Introduction}

The attention-deficit-hyperactivity disorder (ADHD) is one of the most frequently diagnosed psychiatric disorders in children with an estimated worldwide-pooled prevalence of about 
$5.3-8.7 \%$ [1-3], persisting through adolescence and adulthood with a prevalence of up to $5 \%$ $[4,5]$. The core symptoms include increased inattention and/or hyperactivity and impulsivity as well as lack of emotional self-control and motivation.

ADHD is a complex and heterogeneous disorder and its aetiology is not yet completely understood [6]. Despite evidence that environmental factors (i.e. maternal smoking, low birthweight, prematurity) play a significant role in its aetiology, classical genetics studies support a strong genetic contribution for ADHD. The risk of ADHD among parents of children with ADHD is increased by twofold to eightfold compared with the population rate [7]. A meta-analysis of 20 pooled twin studies estimated an average hereditability of $76 \%$, suggesting that ADHD is one of the disorders with the strongest genetic component in psychiatry [7]. Despite these high heritability estimates, identification of genes that confer susceptibility to ADHD has been a slow and difficult process and current findings from both candidate gene studies and genome-wide association studies (GWAS) suggest that ADHD is a polygenic disorder with minor contribution from each individual susceptibility gene [for reviews, see 8, 9]. In particular, it seems likely that the high heritability of ADHD is determined by common variants as well as by rare deletions or duplications known as copy number variants (CNVs) [10]. A useful database on the genomic studies in ADHD is to date available (http:// adhd.psych.ac.cn/index.do).

Multiple neural pathways have been implicated in the development of ADHD and the most studied is the dopaminergic neurotransmission based on the observed dopamine (DA) deficiency in children with ADHD and on the therapeutic benefits provided by methylphenidate (MPH), a DA agonist. A meta-analysis of commonly studied candidate genes has revealed associations between ADHD and variants of the dopamine transporter (DAT1) gene (SLC6A3) and the dopamine D4 and D5 receptor genes (DRD4, DRD5) [11]. Moreover, significant peripheral alterations in norepinephrine (NE) levels and its main metabolites have been observed in ADHD patients [12]. This along with pharmacological evidence support that the noradrenergic system also plays a significant role in the aetiopathogenetic mechanisms of this illness.

\subsection{Diagnosis}

The clinical characterizations, underlying concepts, and nomenclature of the dysfunctions have changed over the time and hyperactive, inattentive, and impulsive children have been described by several authors during the past 200 years. First clinical description of attentional disorders was reported by the German physician, Melchior Adam Weikard, in 1775, and the successive mentioning of ADHD was described in 1902 by the British pediatrician, Sir George Still. In 1952, the APA issued the first DSM but only the second edition included "hyperkinetic impulse disorder". This name was further changed in attention deficit disorder (ADD) with/ without hyperactivity in 1980 (DSM-III). The APA released a revised version of the DSM-III in 1987 where they changed the name definitively to attention-deficit-hyperactivity disorder (ADHD). The three subtypes (combined type ADHD, predominantly inattentive type ADHD, 
predominantly hyperactive-impulsive type ADHD) were established in 2000 (DSM-IV) (for review, see [13]). Recently, NIMH approved the Research Domain Criteria (RDoC) project where a set of assumptions permit to find a new classification system, by integrating genetics, imaging and cognitive information [14]. The RDoC suggests that a biomarker approach to diagnosis may be a more valid way to classify complex mental disorders such as ADHD. Biomarkers offer the opportunity to standardize and improve diagnostic assessment while providing insights into aetiological mechanisms. To date, although biomarkers are successfully used in predicting diseases such as cancer, there is no laboratory test that is used clinically for the diagnosis of ADHD.

\subsection{Treatment}

Pharmacotherapy has an essential role in the treatment of ADHD [15].

Stimulants, such as MPH and dextro-amphetamine (d-AMP), are the most widely used medications approved by the Unites States Food and Drug Administration (US-FDA) for the treatment of ADHD in children [16], and more than 70\% of children with ADHD respond to these drugs [17]. These medications improve both the cognitive (inattention and impulsivity) and the non-cognitive (hyperactivity) domains of the disorder [18]. They have virtually identical clinical effects, although AMP formulations are modestly more efficacious than MPH [19]. Usually, a child who responds to one stimulant drug also responds to the other, presumably because of the similar effect of the drugs on brain monoamine metabolism, and it is generally assumed that the mechanism of at least some effects of these drugs involves DA. In fact, preclinical studies have shown that both stimulants block the re-uptake of DA and NE into the pre-synaptic neuron, and increase the release of these monoamines into the extraneuronal space.

Other drugs used are the monoamine oxidase inhibitors (MAOIs) that block the breakdown of serotonin (5-HT), NE, DA and increase the availability of these monoamines.

Proven alternate choices to stimulant medications include atomoxetine, guanfacine and bupropion. Atomoxetine is a non-stimulant approved by the FDA for the treatment of ADHD. It is in the class of medications known as selective NE re-uptake inhibitors. There is good level of evidence provided by meta-analysis of efficacy for this drug [20-22]. Long-acting guanfacine is in the group of medications known as alpha agonists. These medications were developed for the treatment of high blood pressure but have also been used to treat children with ADHD who have tics, sleep problems and/or aggression. It has recently been approved by the FDA for the treatment of children with ADHD. Finally, bupropion is a unique type of antidepressant that has been less frequently studied as a treatment for ADHD. Like stimulants and atomoxetine, it inhibits the re-uptake of both DA and NE but does not carry the potential risk of abuse and dependence seen with stimulants.

Other alternative treatments, in addition to the behavioural therapy, regard the use of pycnogenol, a herbal dietary supplement derived from French maritime pine bark extract [23] 
or pemoline, a central nervous system (CNS) stimulant, structurally different from AMP and $\mathrm{MPH}$, that acts via enhancing central dopaminergic transmission [24].

Although there are several treatments for ADHD, the mechanisms of action of these agents are still unknown and to date no biological predictors of treatment response are available that can be used in treatment planning.

\subsection{Definition of a biomarker}

The identification of genetic and biochemical markers might facilitate the differential diagnosis of ADHD as well as allow better monitoring of treatment response or prediction of disorder progression, and help to determine treatment strategy and the development of individualized therapies.

According to US-FDA, a biomarker is defined as a characteristic that can be objectively measured and evaluated as an indicator of a normal biological process, a pathogenic process or a response to a therapeutic intervention $[25,26]$.

In other words, the identification of genetic and peripheral biomarkers, which provide molecular signatures of disease, could potentially improve diagnostic classification. Also, the identification and validation of biomarkers for a disorder have the potential application as indicators of disease status, course of the illness and potentially as targets to monitor and predict response to therapeutics.

A desirable diagnostic biomarker should meet several characteristics. In particular, (a) high specificity and sensitivity ( $80 \%$ for both); (b) reliability, reproducibility, inexpensiveness and easy use; (c) independent confirmations by qualified researchers published in peer-reviewed journals; (d) biomarker interpretation should allow comparison with other neurological observations; (e) information provided by a biomarker should be timely and cost-effective with significant clinical usefulness; (f) technology for a test should be available and tolerated by the general target population; (g) methodology should be cheap, simple and easily integrated into a clinical care practice [27].

To date, it is well accepted that a single biomarker is very unlikely to provide enough information to identify cellular and metabolic pathways involved in a particular individual. Thus the identification of a signature set of biomarkers for a disorder each based on their underlying biological pathways will be the most effective for diagnosis and treatment selection [28].

Biological samples useful for a diagnostic test should be ideally non-invasive, which is especially important in psychiatric disorders, since patients often have conditions that should typically not be exacerbated by additional stress. Some studies utilize fluids such as brain tissue or cerebrospinal fluid (CSF), which represent an invasive procedure, whereas urine and saliva are the best non-invasive procedures.

On this basis, the main aims of this chapter are: (a) to identify, among the dopaminergic and noradrenergic molecules strongly associated to aetiopathogenesis of the disorder, potential genetic and biochemical markers linked to ADHD diagnosis; (b) to assess whether treatments can change peripheral levels of a biomarker, to be then useful, if tested, as a response predictor. 


\section{Role of dopaminergic and noradrenergic systems as potential genetic and biochemical markers in ADHD diagnosis}

In this paragraph, we report evidence on the involvement of the most relevant components of dopaminergic and noradrenergic pathways with ADHD aetiopathogenesis as well as with neuropsychological, neuroimaging, treatment response, biochemical and gene expression features. This is to identify, among these molecules, the best potential markers linked to ADHD diagnosis and thus to characterize a putative signature set of genetic and biochemical markers for ADHD. Here, we report positive associations of polymorphisms (single-nucleotide polymorphisms - SNPs and variable number of tandem repeats - VNTR) in different genes (genomics) or alterations in peripheral levels of different proteins (metabolomics) with ADHD.

\subsection{Method}

The literature research was conducted by using two online electronic databases (PubMed http://www.ncbi.nlm.nih.gov/pubmed/, database ADHD http://adhd.psych.ac.cn/index.do) from inception until December 2014, for all available studies on genomics, metabolomics neuropsychological, neuroimaging, dopamine, norepinephrine, metabolites, metabolism enzymes, levels, biochemical, expression, response and "ADHD" or "Attention Deficit Hyperactivity Disorder". Once articles had been collected, bibliographies were manually searched for additional eligible studies. The literature search was performed by two individuals independently.

\subsection{Results}

\subsubsection{Dopamine neurotransmitter system}

The DA hypothesis for ADHD's neurological mechanism is the most probable and studied theory. It is based on a malfunctioning or decreased functioning of the DA system in particular regions of the brain, supported by data derived from pharmacological and neuroimaging studies, from animal models as well as for its involvement in the regulation of functions such as attention or psychomotor activity, which are impaired in ADHD [29].

\subsubsection{Dopamine Transporter Gene (DAT1, SLC6A3)}

The main function played by DAT1 is to regulate DA availability. In particular, it removes DA from the synaptic cleft into the pre-synaptic neuron or releases DA into the extracellular space. Its involvement in the aetiopathogenetic mechanisms of ADHD is supported by the evidence that dopaminergic neurotransmission is controlled by the DAT1 protein, DAT1 is the main target for MPH and AMP, knockout mice for DAT1 present hyperactivity and deficits in inhibitory behaviour, DAT1 has been mapped near to 5p13, a susceptibility locus for ADHD.

The most studied DAT1 variant is a VNTR of 40 base pairs located at the $3^{\prime}$-untranslated region $\left(3^{\prime}\right.$-UTR) of the gene. The ten repeat (10R) and nine repeat (9R) alleles are the most common. A recent meta-analysis that pooled 34 studies on this polymorphism demonstrated an 
association between the 10R allele and ADHD susceptibility [11]. A single successive study replicated this association, with the $10 \mathrm{R}$ allele conferring greater risk for ADHD symptoms [30]. This allele has a functional effect because it correlates with increased DA concentrations in CSF [31] and with higher DAT density in ADHD children in basal ganglia, a brain area participating in inhibitory behaviours [32].

As reported in [33,34], 10R allele was linked to specific neuropsychological and neuroimaging functions and treatment response. In particular, this allele was associated to (a) sustained attention, (b) executive functions, (c) response inhibition, (d) spatial attentional bias, (e) abnormal reward-related ventral striatum activity, (f) diverse patterns of EEG responses, (g) lower IQ, (h) reduced caudate volume, (i) abnormalities in vigilance and EEG activity in response to $\mathrm{MPH}$, (1) higher regional cerebral blood flow and poorer treatment response (Table $1)$.

\subsubsection{Dopamine D4 Receptor (DRD4) gene}

The DRD4 is a G-protein-coupled receptor belonging to the DA D2-like receptor family, which acts to inhibit adenyl cyclase. It is involved in ADHD aetiopathogenetic mechanisms because of its high expression in brain regions implicated in attention and inhibition such as anterior cingulate cortex. Moreover, DRD4 was the first to be associated with personality trait common in ADHD (novelty-seeking).

A highly polymorphic functional VNTR in the third exon has been frequently studied in association studies. It comprises 11 copies of a 48 -bp repeat sequence, where 4,7 and $2 \mathrm{R}$ repeat alleles are the most prevalent. Two meta-analyses confirmed that the $7 \mathrm{R}$ allele was associated with ADHD susceptibility [11,35]. Recently, rare variants and non-synonymous mutations in the VNTR region of 7R allele have been identified in ADHD subjects [36], suggesting an allelic heterogeneity in the VNTR as an important factor in the pathophysiology of ADHD.

As summarized in [33], this allele was associated to (a) cognitive markers such as speed of processing, set shifting, and cognitive impulsiveness, (b) thinner pre-frontal and parietal cortex, (c) enhanced response to MPH. Moreover, mRNA expression levels of DRD4 were lower in ADHD [37] (Table 1).

\subsubsection{Dopamine D5 Receptor (DRD5) Gene}

The DRD5 is a G-protein-coupled receptor that belongs to the D1 class of DA receptors and serves to stimulate adenyl cyclase activity. Some studies support its involvement in ADHD aetiopathogenesis: (a) the expression of this gene is higher in hippocampus, a brain area involved in ADHD pathogenesis; (b) DRD5 is implicated in synaptic strength in hippocampal memory formation. The association between ADHD and a highly polymorphic dinucleotide repeat of DRD5 ((CA)n), at the 5' flanking region, has been the most studied. This variant comprises 12 alleles and the 148-bp and 136-bp alleles are the most common. The 148-bp allele is a risk factor for ADHD according to two meta-analyses [11, 35]. Moreover, it was found associated to some neuropsychological features such as commission errors, omission errors and reaction time variability [33] (Table 1). 


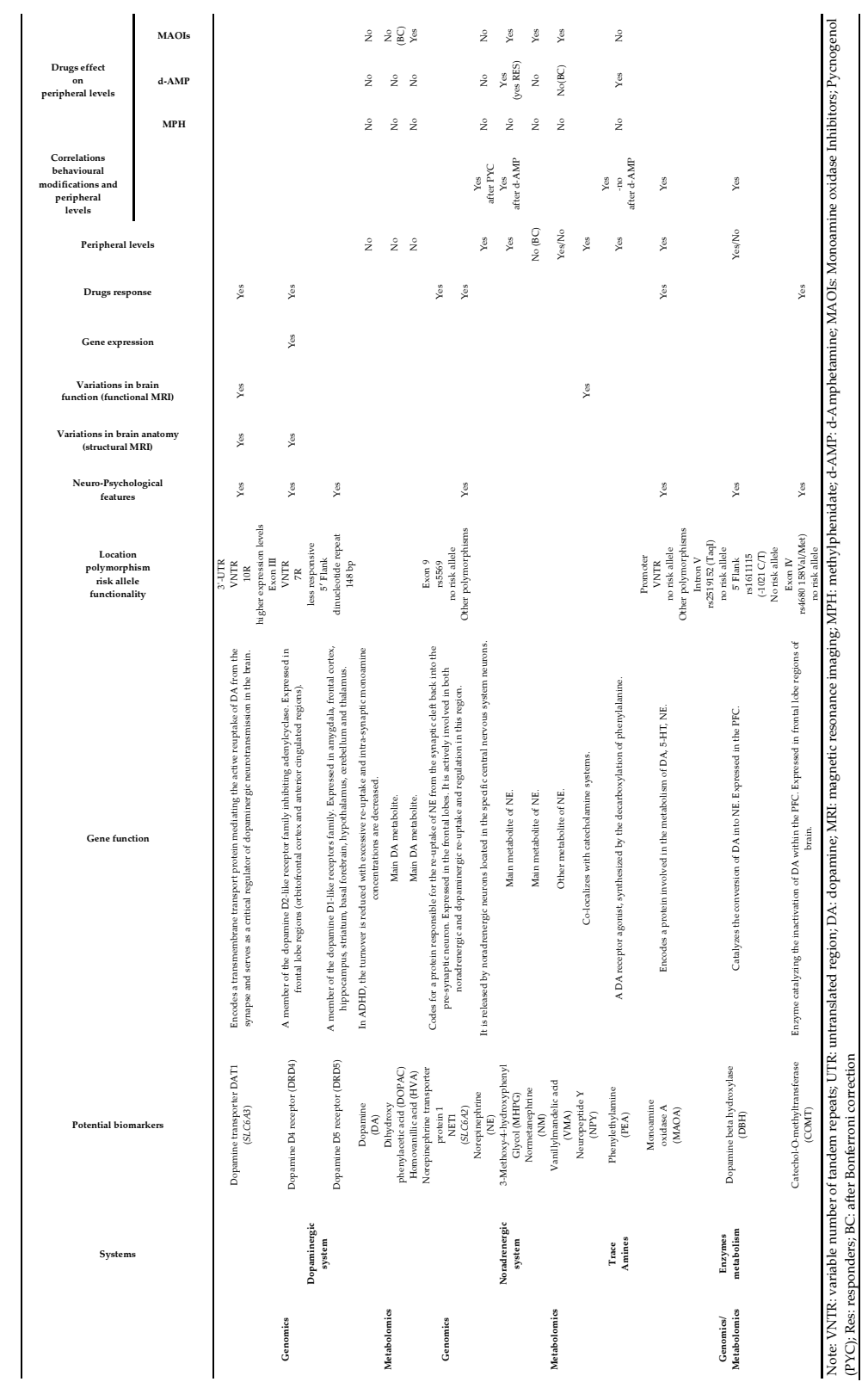

Table 1. Data from genomic and metabolomic studies in dopaminergic, noradrenergic and biogenic trace amines systems and metabolism enzymes classified according to neuropsychological, neuroimaging, treatment response, biochemical and gene expression findings. Results from meta-analyses on the effects of treatments and peripheral levels of the biomarkers. 


\subsubsection{DA, Dihydroxyphenylacetic Acid (DOPAC) and Homovanillic Acid (HVA)}

DA and its main metabolites DOPAC and HVA showed no difference in urine excretion in ADHD patients compared with controls [12] (Table 1).

\subsubsection{Noradrenergic neurotransmitter system}

In 1971, Wender et al. [38] was the first to propose that symptoms usually present in ADHD, such as hyperactivity, inattention and impulsivity, could be the result of abnormalities in the dopaminergic and in noradrenergic neurotransmission system. The authors suggested that noradrenergic system was disturbed in ADHD and that the stimulant medication used to treat these symptoms acted on this neurotransmitter to compensate for the deficit. Indeed after treatment with low dose of MPH, NE efflux increased within the pre-frontal cortex (PFC). Moreover, the presumed method of action of atomoxetine is to increase extracellular levels of NE in PFC.

\subsubsection{Norepinephrine Transporter Gene (NET1, SLC6A2)}

The SLC6A2 gene codes for the norepinephrine transporter, which is responsible for the reuptake of NE from the synaptic cleft back into the pre-synaptic neuron and is targeted by atomoxetine. NET1 is most highly expressed in the frontal lobes where it plays a role in noradrenergic and dopaminergic re-uptake. Although the meta-analysis of the most studied polymorphism of rs5569 or G1287A (exon 9) showed negative results [11], an association was observed in a genome-wide association study [39]. Moreover, allele G was linked to decreasing in mean omission error scores after MPH administration [33] (Table 1).

Although few studies are available, other and different polymorphisms in this gene were associated independently to some neuropsychological tasks and MPH or atomoxetine response [33] (Table 1).

\subsubsection{Norepinephrine (NE)}

A recent meta-analysis [12] on peripheral urinary levels indicated higher concentrations in ADHD compared with controls. (Table 1).

\subsubsection{3-Methoxy-4-Hydroxyphenylglycol (MHPG)}

MHPG is the main metabolite of NE. According to a meta-analysis on its urinary levels [12], the data showed a significant decrease in ADHD patients as compared to controls (Table 1).

\subsubsection{Normetanephrine (NM) and Vanillylmandelic Acid (VMA)}

Other metabolites studied are NM and VMA. According to a recent meta-analysis [12], the urinary levels of NM showed no alterations in patients as compared to controls after Bonferroni correction. Concerning VMA metabolite, contrasting results were reported on its urinary levels [12] (Table 1). 


\subsubsection{Neuropeptide Y (NPY)}

NPY frequently co-localizes with catecholamine systems. It participates in the regulation of feeding, circadian rhythms, reproduction, and thermoregulation. Some studies reported in [12] confirmed increased plasma NPY concentrations in ADHD children compared with controls and an association was observed between gene dose-dependent increases in NPY and emotion processing (Table 1).

\subsubsection{Biogenic trace amines}

\subsubsection{Phenylethylamine (PEA)}

PEA is considered a trace amine because its urinary excretion rate and brain concentration are very low compared to the other catecholamines. In dopaminergic neurons of the nigrostriatal system, PEA is synthesized by the decarboxylation of phenylalanine and has the function to stimulate the release of DA. According to some studies summarized in [12], urinary levels of PEA are significantly lower in patients with ADHD compared with controls. Interestingly, decreased levels of PEA have also been associated with symptoms of inattentiveness (Table 1).

\subsubsection{Metabolism enzymes}

Molecular studies have provided compelling evidence for the association of ADHD with genes that encode enzymes involved in the metabolism of catecholamine and serotonin $[8,9]$.

\subsubsection{Monoamine Oxidase A (MAOA)}

The MAOA gene encodes a protein involved in the metabolism of DA, 5-HT and NE. Different evidence link this gene to aetiopathogenetic mechanisms of ADHD including a MAOA knockout mouse, showing an aggressive behaviour and higher monoaminergic neurotransmitter levels. Recent studies have focused mainly on a functional 30-bp VNTR 1.2 kb upstream of the gene, but according to the meta-analysis [11], no association was found. This VNTR was, however, linked to commission errors attenuated after MPH administration [33]. Other polymorphisms, independently or in combination of haplotypes, were found associated to specific neuropsychological tasks (i.e. motor control or visuo-spatial working memory, reward deficiency or insufficient response inhibition) [33]. Concerning blood levels, the meta-analysis [12] indicated reduced levels in ADHD compared with controls. MAO levels were associated with increased inattention and impulsivity [12] (Table 1).

\subsubsection{Dopamine Beta Hydroxylase (DBH)}

The DBH gene encodes an enzyme that catalyzes the conversion of DA into NE which is particularly expressed in the pre-frontal cortex. The polymorphism intron 5 TaqI (rs2519152) was the most studied, whereas A-1021C/T variant (rs1611115), although a functional polymorphism, was less investigated. A meta-analysisof these variants reported no association with ADHD [11]. 
However, A2/T allele was found associated with several neuropsychological tasks (poorer performances on a temporal order judgment task, more commission and omission errors and greater reaction time variability, more errors on measures of problem-solving and cognitive impulsiveness). An association between neuropsychological measures of executive function in children with ADHD and the $-1021 \mathrm{C} / \mathrm{T}$ variant has also been reported [33]. Concerning the studies on its peripheral levels, patients with ADHD showed lower activities of DBH in serum and urine, whereas no alterations were observed in plasma levels. It was suggested that decreased DBH levels correlate with ADHD symptoms [12] (Table 1).

\subsubsection{Catechol-O-Methyltransferase (COMT)}

The COMT is an enzyme responsible for the degradation of DA and NE. It is highly expressed in frontal lobe where it regulates synaptic DA levels. Most of the association studies between COMT and ADHD susceptibility were focused on the well-known functional polymorphism in exon 4 valine158 methionine (Val158Met). This SNP influences its enzyme activity because homozygotes for the valine allele show greater activity than homozygotes for the methionine allele. A recent meta-analysis [40] indicates no association between ADHD and the Val158Met. However this polymorphism was found associated to (a) some neuropsychological tasks, (b) antisocial and aggressive behaviours of ADHD, (c) response to MPH treatment [33] (Table 1).

\section{Effects of ADHD treatments on peripheral levels of a biomarker in dopaminergic and noradrenergic systems}

Although several treatments for ADHD are available, there are no biological predictors of treatment response that can be used in treatment planning. To address this gap in the literature, we, for the first time, meta-analyzed studies assessing the effects of treatment on biomarkers in dopaminergic, noradrenergic, biogenic trace amines systems and their principal metabolites. The effects of treatments on biomarkers may give insights into their mechanisms of action and could be useful for developing hypotheses about biomarkers that might predict treatment efficacy.

\subsection{METHODS}

\subsubsection{Literature Search}

To identify eligible studies for the meta-analysis, we searched two online electronic databases (PubMed and Human Genome Epidemiology Network, HuGeNet), from inception until December 2014, for all available studies on biomarkers and ADHD treatments in childhood. The diagnostic search terms used to query the databases were "ADHD" and "Attention Deficit Hyperactivity Disorder". These two terms were used to conduct searches with all relevant names of the biomarkers of interest along with different combinations of the following keywords: dopamine, norepinephrine, metabolites, levels, peripheral, blood, urine, treatment, clinical trial, methylphenidate, amphetamine, pemoline, pycnogenol, aspartame. Once articles 
had been collected, bibliographies were manually searched for additional eligible studies. The literature search was performed by two individuals independently.

\subsubsection{Inclusion and Exclusion Criteria}

We included studies that (a) investigated one or more of the peripheral biomarkers described; and (b) provided the features needed for performing meta-analyses. We excluded studies that: (a) compared cases with ADHD with controls; (b) were case reports, (c) were commentaries or reviews, (d) were not in English, (e) used adults or animal models, (f) selected samples based on a disorder other than ADHD.

\subsubsection{Data Extraction for Meta-analyses}

For all studies suitable for meta-analyses, we extracted the following data from the original publications: first author and year of publication, the number of participants, percent males, mean age in years, study designs, biomarkers analyzed, drugs, dosage, treatment time duration, results obtained (Table 2).

\subsubsection{Statistical Analyses}

Review Manager was used to analyze the data (RevMan Version 5.1.6; Copenhagen, The Nordic Cochrane Centre, The Cochrane Collaboration, 2008). As reported in [12], we used the fixed-effects model to generate a pooled effect size and 95\% confidence interval (CI) from individual study effect sizes (the standardized mean difference [SMD]) using the inverse variance method. The significance of the pooled effect sizes was determined by the z-test. Between study, heterogeneity was assessed using a $\chi 2$ test of goodness of fit test and the $I^{2}$ statistic. We used a $p$ value of 0.05 to assert statistical significance. In instances where the results showed a significant effect in the presence of significant between-study heterogeneity, a random effects model was used, with effect sizes pooled using the DerSimonian and Laird method.

Publication bias was estimated by the method of Egger et al. [41] which uses a linear regression approach to measure funnel plot asymmetry on the natural logarithm scale of the OR. The significance of the intercept (a) was determined by the $t$ test [41]. The rank correlation method and regression method tests were conducted by MIX version 1.7. (http://www.mix-for-metaanalysis.info).

Because we conducted 8 meta-analyses to assess the significance of biomarkers, our Bonferroni corrected significance level was 0.006 .

\subsubsection{Behavioural methods}

The main scales to address behavioural modifications/response to drugs were Conners Teacher/Parent Rating Scales [42-54, 23]. Moreover, other tests/scales were used: Physical and Neurological Examination for Soft Signs [47, 53, 46, 55], Multigrade Inventory for Teachers, Matching Familiar Figures Test, Children's Checking Task, Wisconsin Card Sorting Test, Airplane Test [42], Children's Global Assessment and Impression Scales, Child (Attention Problems) Teacher Rating scale, Wechsler Intelligence Scale for Children [47, 54, 23]. 


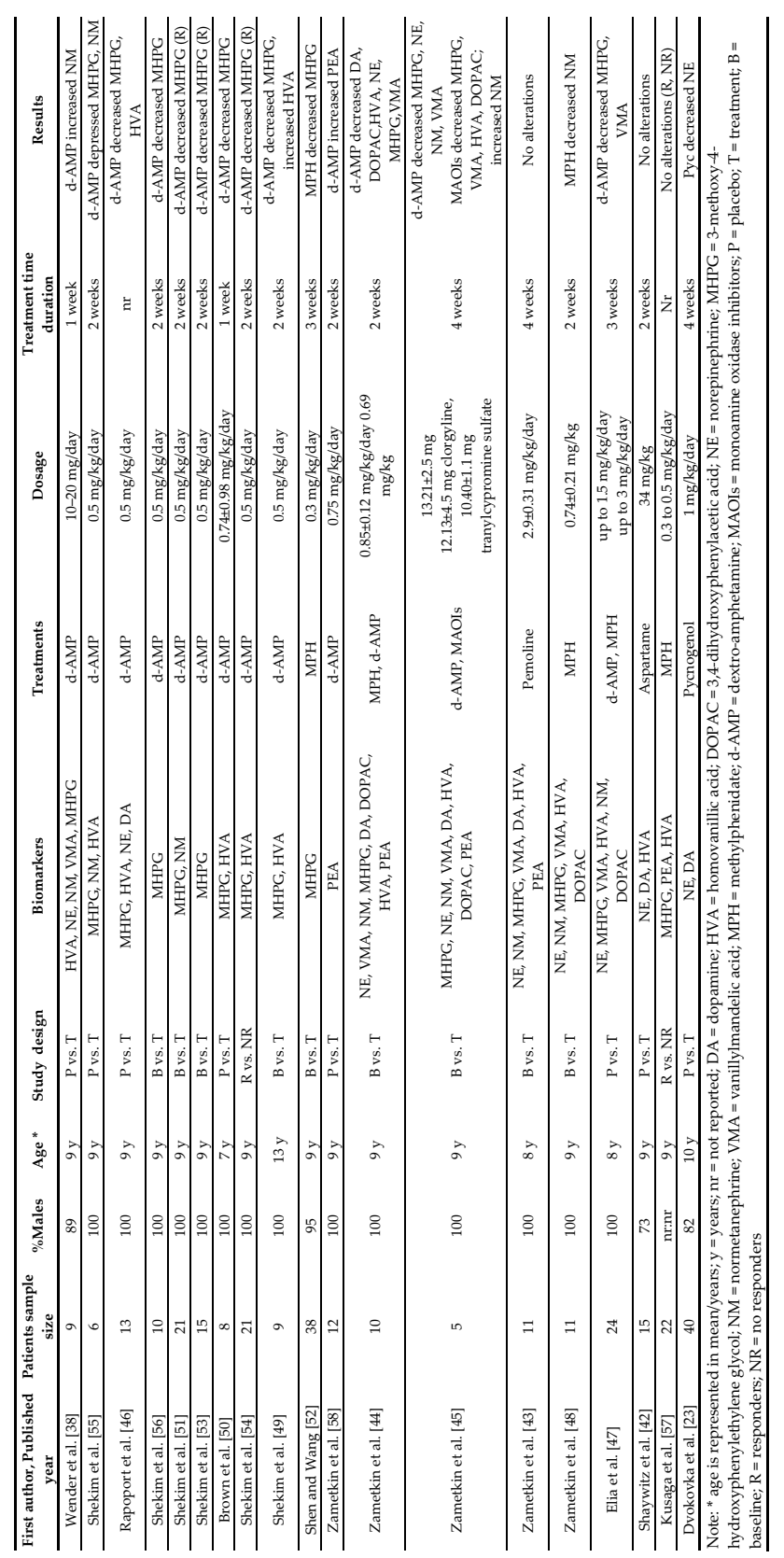

Table 2. Summary of studies on the ADHD treatments and peripheral levels of biomarkers in dopaminergic, noradrenergic and biogenic trace amines systems included in the meta-analyses. 


\subsection{Results}

After screening of papers according to the inclusion/exclusion criteria, 35 ADHD treatments studies that focused on alterations in the principal metabolites and metabolism enzymes of dopaminergic and noradrenergic neurotransmission pathways were reported.

The main studies suitable for performing meta-analyses on ADHD treatments and peripheral biomarkers in dopaminergic, noradrenergic and biogenic trace amines systems are described in Table 2.

All the analyses presented below use the SMD as the effect size.

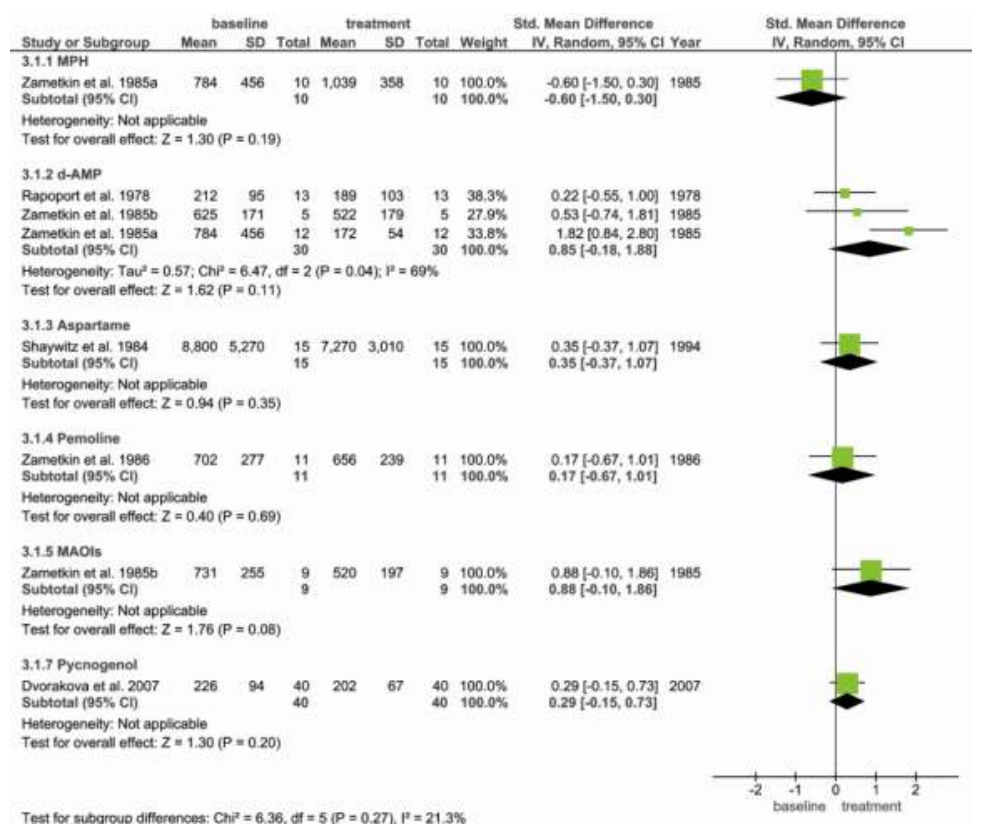

Captions: $\mathrm{Chi}^{2}=\chi^{2}$ test of goodness of fit; $\mathrm{Tau}^{2}=$ estimate of the between-study variance in a random-effects metaanalysis; methylphenidate (MPH); dextroamphetamine (d-AMP); monoamine oxidase inhibitors (MAOIs).

Figure 1. Random forest plot for standard mean differences (SMD) from meta-analysis of urinary dopamine (DA) levels.

\subsubsection{Dopamine neurotransmitter system}

\subsubsection{DA and DOPAC}

Urinary levels of DA [23, 42-46] and its metabolite DOPAC [47, 48, 44, 45] were investigated in several studies included in the meta-analyses. The results indicated no alteration in DA levels after d-AMP treatment $(Z=1.62 p=0.11)$, with a slight heterogeneity in effect sizes among the studies $\left(p=0.04, I^{2}=69 \%\right)$. Other treatments ( $\mathrm{MPH}$, aspartame, pemoline, MAOIs, pycno- 
genol) did not influence its levels (Figure 1). No clinically significant effect on the behaviour and cognitive status of children with ADHD was observed after aspartame, pemoline, pcynogenol and MAOIs [42, 45, 43, 23], as well as in relation to d-AMP treatments.

Similarly, urinary DOPAC levels were similar between treated and not-treated patients with ADHD both after MPH $(Z=0.08, p=0.93)$ and after d-AMP $(Z=1.10, p=0.27)$ treatment. Significant heterogeneity in effect sizes across studies was observed for d-AMP $\left(p=0.0001, I^{2}\right.$ $=89 \%)$. The difference observed after MAOIs treatment $(Z=2.38, p=0.02)$ was lost after Bonferroni correction (Figure 2) and no clinical effect in children with ADHD was observed [45]. Similarity, there were no correlations between DOPAC levels and behavioural improvements after MPH and d-AMP treatments.

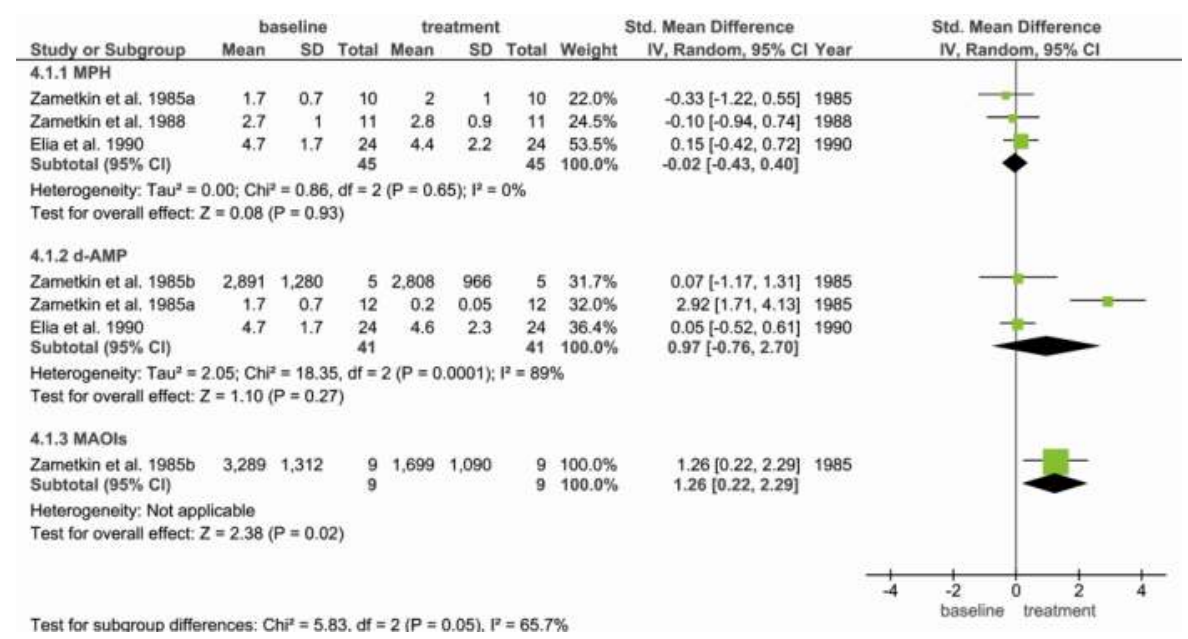

Captions: $\mathrm{Chi}^{2}=\chi^{2}$ test of goodness of fit; $\mathrm{Tau}^{2}=$ estimate of the between-study variance in a random-effects metaanalysis; methylphenidate (MPH); dextroamphetamine (d-AMP); monoamine oxidase inhibitors (MAOIs).

Figure 2. Random forest plot for standard mean differences (SMD) from meta-analysis of urinary metabolite dihydroxyphenylacetic acid (DOPAC) levels.

\subsubsection{Homovanilic Acid (HVA)}

Eleven studies assessed the DA metabolite HVA in urine [42, 47, 48, 43-45, 49, 50, 46, 55, 38]. No alterations in HVA levels were observed after MPH $(Z=0.09, p=0.93)$ and after d-AMP $(Z=1.76, p=0.08)$ treatment. Significant heterogeneity in effect sizes across studies was observed after d-AMP treatment $\left(p=0.0001, I^{2}=76 \%\right)$. Only one study [45] reported reduced HVA levels after MAOIs treatment $(Z=3.46, p=0005)$, but no correlation with behavioural features was observed (Figure 3). No clinical effect on the behaviour and cognitive status of children with ADHD was observed after aspartame, pemoline and MAOIs [42, 45, 43], as well as after MPH and d-AMP treatments. 


\begin{tabular}{|c|c|c|c|c|c|c|c|c|c|c|c|}
\hline \multirow{3}{*}{$\begin{array}{l}\text { Study or Subgroup } \\
6.2 .1 \mathrm{MPH}\end{array}$} & \multicolumn{3}{|c|}{ baseline } & \multicolumn{3}{|c|}{ treatment } & & \multirow{2}{*}{\multicolumn{2}{|c|}{$\begin{array}{l}\text { Std. Mean Difference } \\
\text { IV, Random, } 95 \% \mathrm{Cl}\end{array}$}} \\
\hline & \multicolumn{3}{|c|}{ Mean SD Total } & \multirow[t]{2}{*}{ Mean } & \multirow[t]{2}{*}{ SD } & \multirow[t]{2}{*}{ Total } & \multirow[t]{2}{*}{ Weight } & \multicolumn{2}{|c|}{$\begin{array}{l}\text { Std. Mean Difference } \\
\text { IV, Random, 95\% CI Year }\end{array}$} & & \\
\hline & & & & & & & & & & & \\
\hline Zametkin et al. 1985a & 3.4 & 1.1 & 12 & 4.1 & 1.7 & 10 & $23.2 \%$ & $-0.48[-1.33,0.37]$ & 1985 & & \\
\hline Zametkin et al. 1988 & 4.7 & 1.1 & 11 & 4.6 & 1 & 11 & $24.2 \%$ & $0.09[-0.74,0.93]$ & 1988 & & \\
\hline Elia et al. 1990 & 28.3 & 5 & 24 & 27 & 7.3 & 24 & $52.6 \%$ & $0.20[-0.36,0.77]$ & 1990 & & \\
\hline Subtotal $(95 \% \mathrm{Cl})$ & & & 47 & & & 45 & $100.0 \%$ & $0.02[-0.39,0.43]$ & & & \\
\hline \multicolumn{12}{|c|}{$\begin{array}{l}\text { Heterogeneity: } \text { Tau }^{2}=0.00 ; \mathrm{Chi}^{2}=1.75, \mathrm{df}=2(\mathrm{P}=0.42) ; \mathrm{P}^{2}=0 \% \\
\text { Test for overall effect: } Z=0.09(P=0.93)\end{array}$} \\
\hline \multicolumn{12}{|l|}{ 6.2.2 d-AMP } \\
\hline Wender et al. 1971 & 3.4 & 2.1 & 9 & 2.7 & 1.7 & 9 & $13.0 \%$ & $0.35[-0.58,1.28]$ & 1971 & & \\
\hline Shekim et al. 1977 & 5.2 & 1 & 6 & 5 & 1.3 & 6 & $11.7 \%$ & $0.16[-0.98,1.29]$ & 1977 & & \\
\hline Rapoport et al. 1978 & 4.2 & 1.9 & 13 & 2.9 & 1.1 & 13 & $13.9 \%$ & $0.81[0.01,1.62]$ & 1978 & & \\
\hline Brown et al. 1981 & 5.7 & 1.2 & 8 & 5.4 & 0.8 & 8 & $12.7 \%$ & $0.28[-0.71,1.26]$ & 1981 & & \\
\hline Shekim et al 1983 & 3.6 & 1.4 & 9 & 5.2 & 2.6 & 9 & $12.8 \%$ & $-0.73[-1.69,0.23]$ & 1983 & & \\
\hline Zametkin et al. 1985a & 3.4 & 1.1 & 12 & 0.2 & 0.05 & 12 & $9.7 \%$ & $3.97[2.50,5.43]$ & 1985 & & \\
\hline Zametkin et al. 1985b & 4.5 & 1.1 & 5 & 4.3 & 0.6 & 5 & $11.0 \%$ & $0.20[-1.04,1.45]$ & 1985 & & \\
\hline Elia et al. 1990 & 28.3 & 5 & 24 & 25 & 5.2 & 24 & $15.2 \%$ & $0.64[0.06,1.22]$ & 1990 & & \\
\hline Subtotal $(95 \% \mathrm{CI})$ & & & 86 & & & 86 & $100.0 \%$ & $0.62[-0.07,1.31]$ & & & \\
\hline \multirow{2}{*}{\multicolumn{12}{|c|}{$\begin{array}{l}\text { Heterogeneity: } \text { Tau }^{2}=0.73 ; \mathrm{Ch}^{2}=29.39, \mathrm{df}=7(P=0.0001) ; \mathrm{I}^{2}=76 \% \\
\text { Test for overall effect: } Z=1.76(P=0.08)\end{array}$}} \\
\hline & & & & & & & & & & & \\
\hline \multicolumn{12}{|l|}{ 6.2.3 Aspartame } \\
\hline Shaywitz et al. 1984 & 173 & 89 & 15 & 179 & 45 & 15 & $100.0 \%$ & $-0.08[-0.80,0.63]$ & 1994 & & \\
\hline Subtotal $(95 \% \mathrm{CI})$ & & & 15 & & & 15 & $100.0 \%$ & $-0.08[-0.80,0.63]$ & & & \\
\hline \multicolumn{12}{|c|}{ Heterogeneity: Not applicable } \\
\hline \multicolumn{12}{|c|}{ Test for overall effect: $Z=0.23(P=0.82)$} \\
\hline \multicolumn{12}{|l|}{ 6.2.4 Pemoline } \\
\hline Zametkin et al. 1986 & 4.3 & 1.5 & 11 & 3.2 & 1.2 & 11 & $100.0 \%$ & $0.78[-0.09,1.65]$ & 1986 & & \\
\hline Subtotal $(95 \% \mathrm{CI})$ & & & 11 & & & 11 & $100.0 \%$ & $0.78[-0.09,1.65]$ & & & \\
\hline \multicolumn{12}{|c|}{ Heterogeneity: Not applicable } \\
\hline \multicolumn{12}{|c|}{ Test for overall effect: $Z=1.75(P=0.08)$} \\
\hline \multicolumn{12}{|l|}{ 6.2.6 MAOls } \\
\hline Zametkin et al. 1985b & 3.9 & 0.9 & 9 & 1.5 & 1.2 & 9 & $100.0 \%$ & $2.15[0.94,3.37]$ & 1985 & & \\
\hline Subtotal $(95 \% \mathrm{Cl})$ & & & 9 & & & 9 & $100.0 \%$ & $2.15[0.94,3.37]$ & & & \\
\hline \multirow{2}{*}{\multicolumn{12}{|c|}{$\begin{array}{l}\text { Heterogeneity: Not applicable } \\
\text { Test for overall effect: } Z=3.46(P=0.0005)\end{array}$}} \\
\hline & & & & & & & & & & & \\
\hline & & & & & & & & & & $\begin{array}{cccc}1 & 1 & 1 & 1 \\
-4 & -2 & 0 & 2 \\
\text { baseline } & \text { treatment }\end{array}$ & 4 \\
\hline
\end{tabular}

Captions: $\mathrm{Chi}^{2}=\chi^{2}$ test of goodness of fit; $\mathrm{Tau}^{2}=$ estimate of the between-study variance in a random-effects metaanalysis; methylphenidate (MPH); dextroamphetamine (d-AMP); monoamine oxidase inhibitors (MAOIs).

Figure 3. Random forest plot for standard mean differences (SMD) from meta-analysis of urinary homovanilic acid (HVA) levels.

\subsubsection{Noradrenergic neurotransmitter system}

\subsubsection{1. $N E$}

Our meta-analyses for NE included nine studies [23, 42, 47, 48, 43-46, 38] and showed no difference in urinary levels in treated patients with ADHD compared with those not treated (MPH: $Z=0.81, p=0.42$; d-AMP $Z=1.55, p=0.12$ ), with heterogeneity in effect sizes across studies for d-AMP ( $p=0.0002, I^{2}=82 \%$ ) (Figure 4$)$. Significant reduction of urinary NE was observed after pycnogenol treatment $(Z=3.08, p=0.002)$ (Figure 4$)$, with consequently less hyperactivity [23] (Table 1). No clinical effect on the behaviour and cognitive status of children with ADHD was observed after aspartame, pemoline and MAOIs [42, 45, 43] and similarly with MPH and d-AMP treatments. 


\begin{tabular}{|c|c|c|c|c|c|c|c|c|c|c|c|c|c|}
\hline \multirow[b]{2}{*}{ Study or Subgroup } & \multicolumn{3}{|c|}{ baseline } & \multicolumn{3}{|c|}{ treatment } & \multicolumn{3}{|c|}{ Std. Mean Difference } & \multirow{2}{*}{\multicolumn{4}{|c|}{$\begin{array}{l}\text { Std. Mean Difference } \\
\text { IV, Random, } 95 \% \mathrm{Cl}\end{array}$}} \\
\hline & Mean & SD & Total & Mean & SD & Total & Weight & IV, Random, $95 \% \mathrm{Cl}$ & Year & & & & \\
\hline \multicolumn{14}{|l|}{ 9.2.1 MHP } \\
\hline Zametkin et al. 1985a & 120 & 38.3 & 10 & 177 & 62.5 & 10 & $26.3 \%$ & $-1.05[-2.00,-0.10]$ & 1985 & & & & \\
\hline Zametkin et al. 1988 & 76.5 & 17.4 & 11 & 75.5 & 15.9 & 11 & $30.4 \%$ & $0.06[-0.78,0.89]$ & 1988 & & & & \\
\hline Elia et al. 1990 & 0.4 & 0.2 & 24 & 0.4 & 0.3 & 24 & $43.3 \%$ & $0.00[-0.57,0.57]$ & 1990 & & & & \\
\hline \multirow{2}{*}{\multicolumn{14}{|c|}{$\begin{array}{l}\text { Heterogeneity: } \text { Tau }^{2}=0.15 ; \mathrm{Chi}^{2}=3.95, \mathrm{df}=2(\mathrm{P}=0.14) ; \mathrm{l}^{2}=49 \% \\
\text { Test for overall effect: } \mathrm{Z}=0.81(\mathrm{P}=0.42)\end{array}$}} \\
\hline & & & & & & & & & & & & & \\
\hline \multicolumn{14}{|l|}{ 9.2.2 d-AMP } \\
\hline Wender et al. 1971 & 38.3 & 5.2 & 9 & 41.5 & 13.6 & 9 & $20.5 \%$ & $-0.30[-1.23,0.63]$ & 1971 & & & & \\
\hline Rapoport et al. 1978 & 31.2 & 12.8 & 13 & 25.3 & 11.5 & 13 & $21.7 \%$ & $0.47[-0.31,1.25]$ & 1978 & & & & \\
\hline Zametkin et al. 1985a & 120 & 38.3 & 12 & 32.4 & 10.2 & 12 & $17.9 \%$ & $3.02[1.79,4.25]$ & 1985 & & & & \\
\hline Zametkin et al. 1985b & 96.4 & 25.4 & 5 & 66.8 & 24.8 & 5 & $16.6 \%$ & $1.07[-0.31,2.44]$ & 1985 & & & & \\
\hline Elia et al. 1990 & 0.4 & 0.2 & 24 & 0.4 & 0.2 & 24 & $23.3 \%$ & $0.00[-0.57,0.57]$ & 1990 & & & & \\
\hline Subtotal $(95 \%$ Cl) & & & 63 & & & 63 & $100.0 \%$ & $0.76[-0.20,1.72]$ & & & & & \\
\hline \multicolumn{14}{|c|}{$\begin{array}{l}\text { Heterogeneity: } \text { Tau }^{2}=0.94 ; \mathrm{Chi}^{2}=22.39, \text { df }=4(P=0.0002) ; \mathrm{l}^{2}=82 \% \\
\text { Test for overall effect: } Z=1.55(P=0.12)\end{array}$} \\
\hline \multicolumn{14}{|l|}{ 9.2.3 Aspartame } \\
\hline $\begin{array}{l}\text { Shaywitz et al. } 1984 \\
\text { Subtotal }(95 \% \mathrm{Cl})\end{array}$ & 897 & 977 & $\begin{array}{l}15 \\
15\end{array}$ & 614 & 324 & $\begin{array}{l}15 \\
15\end{array}$ & $\begin{array}{l}100.0 \% \\
100.0 \%\end{array}$ & $\begin{array}{l}0.38[-0.34,1.10] \\
0.38[-0.34,1.10]\end{array}$ & 1994 & & & & \\
\hline \multicolumn{14}{|c|}{ Heterogeneity: Not applicable } \\
\hline \multicolumn{14}{|c|}{ Test for overall effect: $Z=1.03(P=0.31)$} \\
\hline \multicolumn{14}{|l|}{ 9.2.4 Pemoline } \\
\hline $\begin{array}{l}\text { Zametkin et al. } 1986 \\
\text { Subtotal }(95 \% \mathrm{CI})\end{array}$ & 112 & 55 & $\begin{array}{l}11 \\
11\end{array}$ & 101 & 40 & $\begin{array}{l}11 \\
11\end{array}$ & $\begin{array}{l}100.0 \% \\
100.0 \%\end{array}$ & $\begin{array}{l}0.22[-0.62,1.06] \\
0.22[-0.62,1.06]\end{array}$ & 1986 & & & & \\
\hline \multicolumn{14}{|c|}{ Heterogeneity: Not applicable } \\
\hline \multicolumn{14}{|c|}{ Test for overall effect: $Z=0.51(P=0.61)$} \\
\hline \multicolumn{14}{|l|}{ 9.2.5 Pycnogenol } \\
\hline $\begin{array}{l}\text { Dvorakova et al. } 2007 \\
\text { Subtotal }(95 \% \mathrm{Cl})\end{array}$ & 24.1 & 1.1 & $\begin{array}{l}40 \\
40\end{array}$ & 19.9 & 8.2 & $\begin{array}{l}40 \\
40\end{array}$ & $\begin{array}{l}100.0 \% \\
100.0 \%\end{array}$ & $\begin{array}{l}0.71[0.26,1.16] \\
0.71[0.26,1.16]\end{array}$ & 2007 & & & & \\
\hline \multicolumn{14}{|c|}{ Heterogeneity: Not applicable } \\
\hline \multicolumn{14}{|c|}{ Test for overall effect: $Z=3.08(P=0.002)$} \\
\hline \multicolumn{14}{|l|}{ 9.2.6 MAOls } \\
\hline $\begin{array}{l}\text { Zametkin et al. } 1985 \mathrm{~b} \\
\text { Subtotal }(95 \% \mathrm{Cl})\end{array}$ & 99 & 22.6 & $\begin{array}{l}9 \\
9\end{array}$ & 85.1 & 84.7 & $\begin{array}{l}9 \\
9\end{array}$ & $\begin{array}{l}100.0 \% \\
100.0 \%\end{array}$ & $\begin{array}{l}0.21[-0.71,1.14] \\
0.21[-0.71,1.14]\end{array}$ & 1985 & & & & \\
\hline \multirow{2}{*}{\multicolumn{14}{|c|}{$\begin{array}{l}\text { Heterogeneity: Not applicable } \\
\text { Test for overall effect: } Z=0.45(P=0.65)\end{array}$}} \\
\hline & & & & & & & & & & & & & \\
\hline & & & & & & & & & & -4 & $\begin{array}{l}-2 \\
\text { baseline }\end{array}$ & $0 \quad 2$ & 4 \\
\hline
\end{tabular}

Captions: $\mathrm{Chi}^{2}=\chi^{2}$ test of goodness of fit; $\mathrm{Tau}^{2}=$ estimate of the between-study variance in a random-effects metaanalysis; methylphenidate (MPH); dextroamphetamine (d-AMP); monoamine oxidase inhibitors (MAOIs).

Figure 4. Random forest plot for standard mean differences (SMD) from meta-analysis of urinary norepinephrine (NE) levels.

\subsubsection{Methoxy-4-hydroxyphenylglycol (MHPG)}

Another widely studied metabolite of NE is MHPG. Fourteen studies provided data for our meta-analysis $[47,48,43-45,52,49,50,56,51,53,46,55,38]$. We found significantly lower urinary MHPG levels in treated compared with not-treated patients after d-AMP treatment $(d=0.89, Z=6.23, p<0.00001)$, significant after Bonferroni correction. No heterogeneity of effect sizes across studies was observed. Concerning the results about $\mathrm{MPH}$, a trend of significance 
was reported $(Z=1.85, p=0.06)$, but it was lost after Bonferroni correction. Only one study reported a significant decrease after MAOIs treatment $(Z=4.21, p<0.0001)$ [45] (Figure 5).

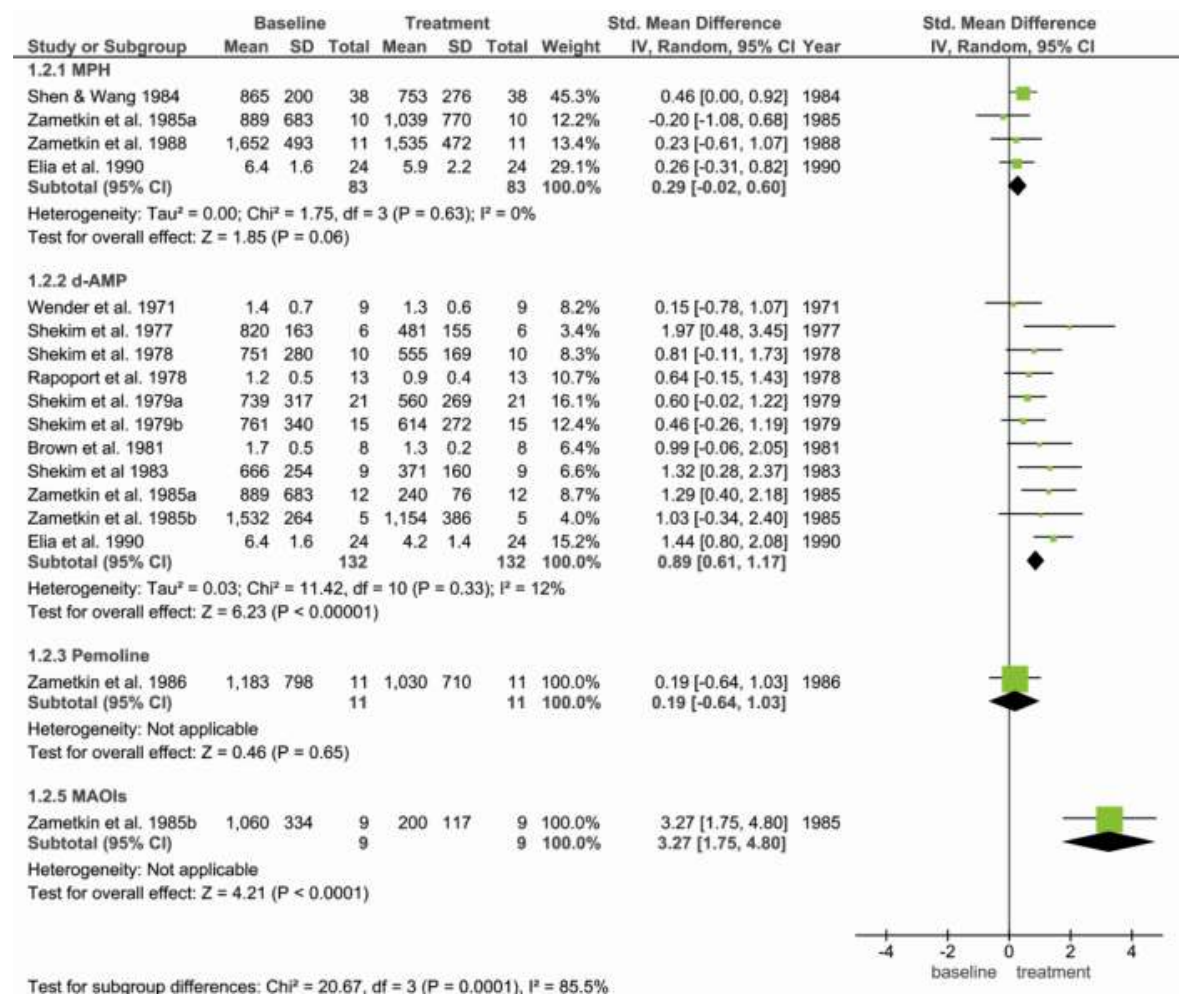

Captions: $\mathrm{Chi}^{2}=\chi^{2}$ test of goodness of fit; $\mathrm{Tau}^{2}=$ estimate of the between-study variance in a random-effects metaanalysis; methylphenidate (MPH); dextroamphetamine (d-AMP); monoamine oxidase inhibitors (MAOIs).

Figure 5. Random forest plot for standard mean differences (SMD) from meta-analysis of urinary 3-methoxy-4-hydroxyphenylethylene glycol (MHPG) levels.

Moreover, with the aim to assess whether MHPG can be a potential predictor of the treatment response, we have meta-analyzed studies that reported MHPG urinary levels among responders and no responders pre- and post-treatment $[57,54,53,51]$. The results indicated that MHPG urinary levels are reduced by stimulants in the responders $(Z=2.66, p=0.008)$ but not in the no-responders $(Z=0.16, p=0.87)$ (Figure 6).

Significant correlations were observed between lower levels of MHPG and behavioural improvements after d-AMP administration [45, 49, 54, 50, 51, 53] (Table 1), whereas no significant correlation was observed after MPH [48], or MAOIs [45] or pemoline [43] treatments. 


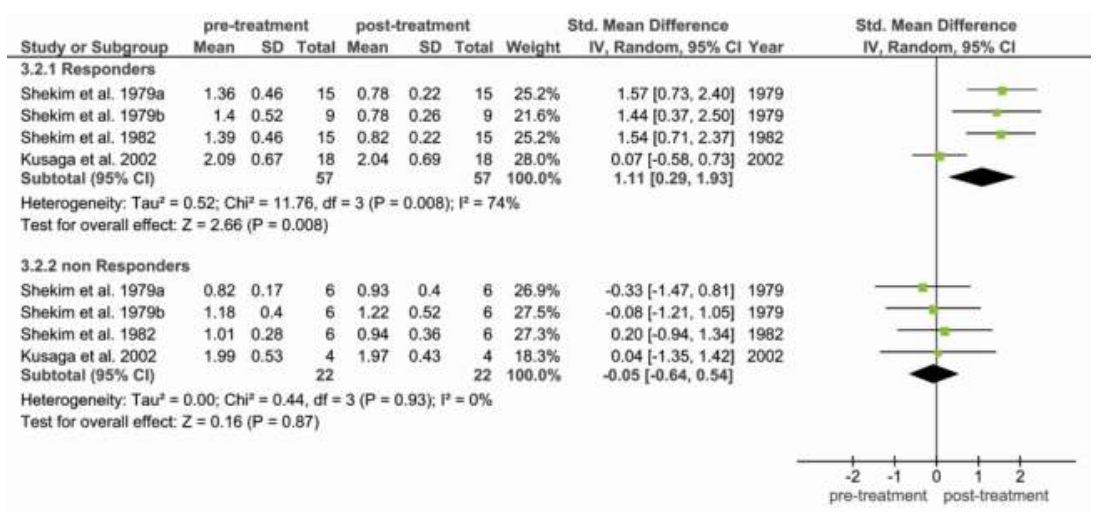

Captions: $\mathrm{Chi}^{2}=\chi^{2}$ test of goodness of fit; $\mathrm{Tau}^{2}=$ estimate of the between-study variance in a random-effects metaanalysis.

Figure 6. Random forest plot for standard mean differences (SMD) from meta-analysis of urinary 3-methoxy-4-hydroxyphenylethylene glycol (MHPG) levels in responders and no responders and pre-post d-AMP treatment.

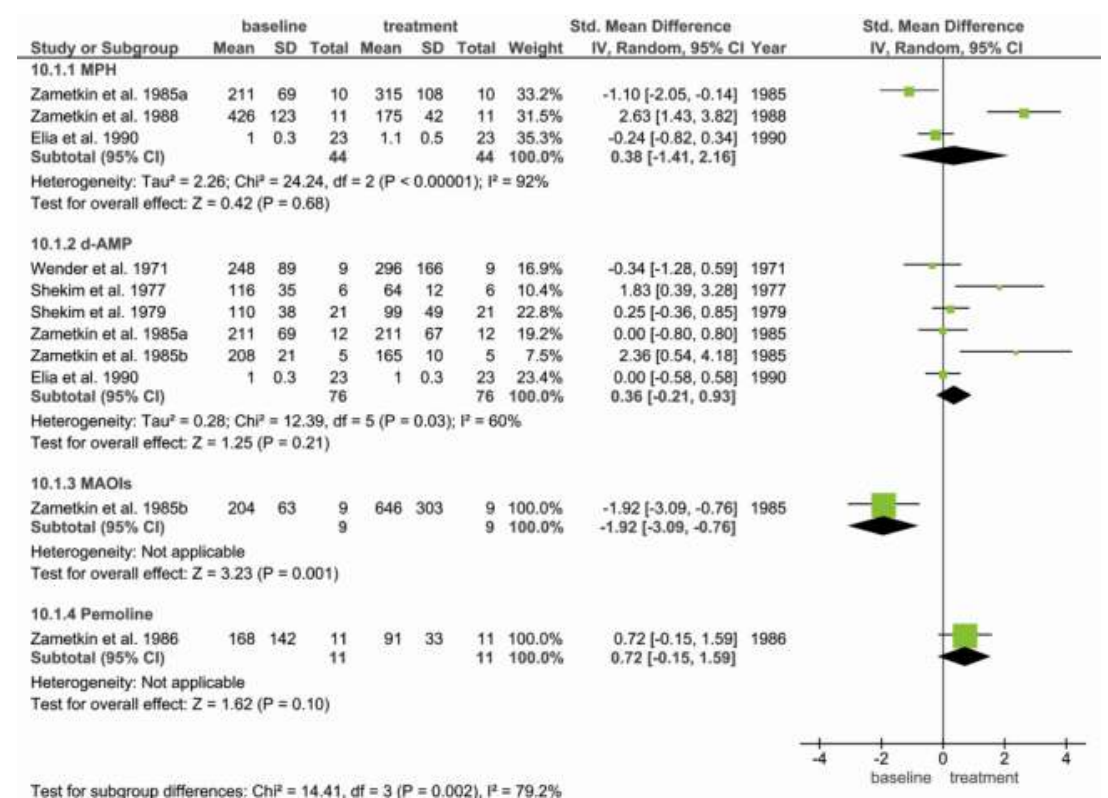

Captions: $\mathrm{Chi}^{2}=\chi^{2}$ test of goodness of fit; $\mathrm{Tau}^{2}=$ estimate of the between-study variance in a random-effects metaanalysis; methylphenidate (MPH); dextroamphetamine (d-AMP); monoamine oxidase inhibitors (MAOIs).

Figure 7. Random forest plot for standard mean differences (SMD) from meta-analysis of urinary normetanephrine (NM) levels. 
Following the Egger et al. [41] method, we have tested the presence of publication bias (is a bias with regard to what is likely to be published, among what is available to be published) for all biomarkers analyzed. Only in the case of MHPG, we observed a slight significant presence of publication bias ( $p=0.05$, data not shown). However when the study from Zametkin et al. [45] was excluded, this difference disappears ( $p=0.21$, data not shown).

\subsubsection{Normetanephrine (NM)}

The main metabolite of NE is NM. The meta-analysis of NM included eight studies [47, 48, 43$45,51,55,38]$. No differences in urinary NM levels were observed between treated and nottreated patients after MPH $(Z=0.42, p=0.68)$ and after d-AMP $(Z=1.25, p=0.21)$ treatments, with heterogeneity of effect sizes across studies for MPH $\left(p<0.00001, I^{2}=92 \%\right)$. One study reported no alteration after pemoline treatment, with no correlation with behavioural improvements [43] and one study indicated increased levels of NM after MAOIs treatment with no evidence of correlation with behavioural features $(Z=3.23, p=0.001)$ [45] (Figure 7).

\subsubsection{Vanillylmandelic Acid (VMA)}

Other metabolites studied are VMA. Six studies were available for meta-analyses [47, 48, 43$45,38]$ and the results indicated significant difference after d-AMP treatment $(Z=2.12, p=0.03)$ but lost after Bonferroni correction. Significant difference was observed for the presence of heterogeneity in effect size across the studies $\left(p<0.0001, I^{2}=86 \%\right)$. Reduced levels of VMA after MAOIs treatment were observed in only one study [45] $(Z=4.45, p<0.00001)$, in absence of significant correlation with behavioural improvements. Moreover, no alteration was observed after pemoline treatment along with no clinically significant effect on the behaviour of children with ADHD [43] (Figure 8).

\subsubsection{Biogenic trace amines}

\subsubsection{PEA}

Although there are not enough studies for performing meta-analysis, administration of d-AMP resulted in an increased urinary excretion of PEA [44, 58, 57]. However, no correlation was observed between PEA levels and the ADHD severity [57, 58] (Table 1). No alterations were observed after MPH, MAOIs, and pemoline treatments [43-45].

\section{Discussion and future research}

This chapter has two main aims: (a) to define a hypothetical signature of a set of genetic and biochemical markers useful for the ADHD diagnosis; (b) to determine whether the treatment changes the levels of a biomarker to be useful, if tested, as a predictor of treatment response. In Table 1, we summarized the results obtained from this work, providing an overview of the significant findings that emerged by the different analyses. 


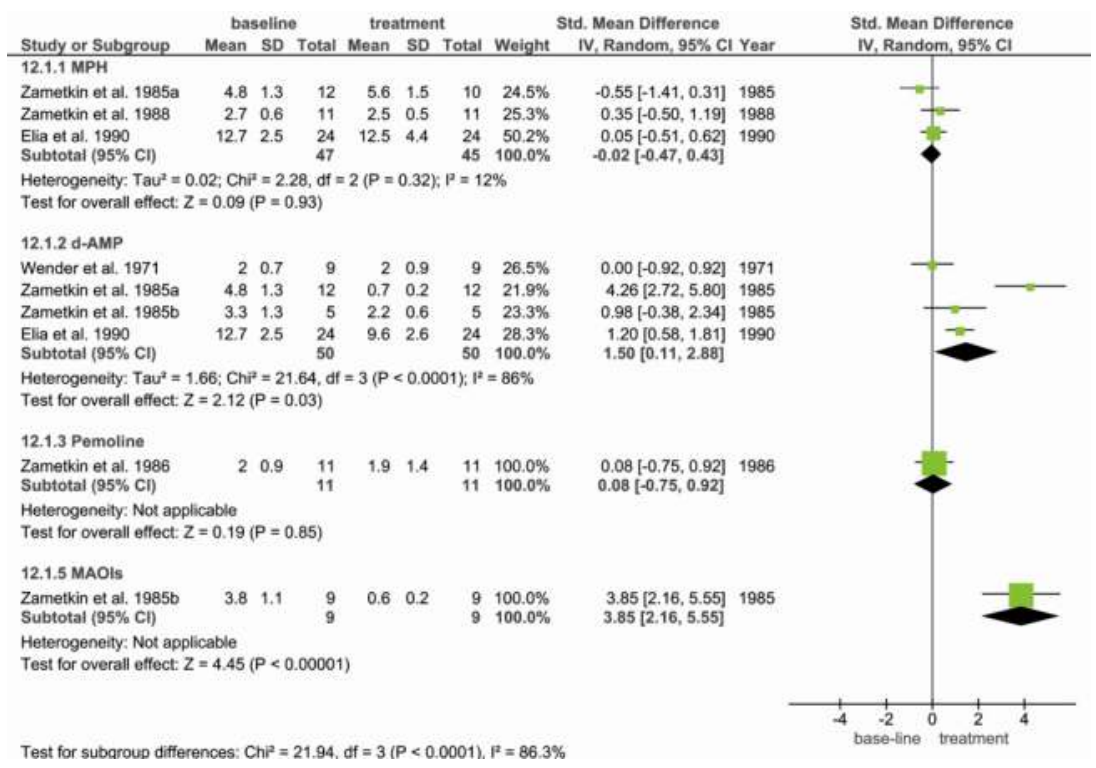

Captions: $\mathrm{Chi}^{2}=\chi^{2}$ test of goodness of fit; $\mathrm{Tau}^{2}=$ estimate of the between-study variance in a random-effects metaanalysis; methylphenidate (MPH); dextroamphetamine (d-AMP); monoamine oxidase inhibitors (MAOIs).

Figure 8. Random forest plot for standard mean differences (SMD) from meta-analysis of urinary vanillylmandelic acid (VMA) levels.

Starting from the literature, we support evidence that SLC6A3 and DRD4 represent the best potential genetic markers for ADHD diagnosis. As reported in [33], allele 10R in SLC6A3 gene, susceptibility risk allele and associated to higher DA concentrations and higher DAT1 density in basal ganglia, is linked to different and specific neuropsychological tasks, generates more activation in specific brain areas, reduced brain structure and is associated to drugs response. Interestingly a reverse association has been seen for ADHD adults where it is the 9R instead of $10 \mathrm{R}$, the risk allele [59]. This suggests that this allele can be a good candidate also for discriminating ADHD in children vs. ADHD in adults.

Similarly 7R in DRD4 gene, susceptibility risk allele and linked to less responsivity to DA, is involved in some cognitive features, brain structure and functioning, drugs response and expression levels of DRD4.

In the second line, we co-localize the metabolite MHPG, the enzyme MAOA, NE and SLC6A2 as good candidates as markers for ADHD. They were found associated to peripheral levels altered in ADHD, to some neuropsychological tasks, treatment response and symptomatology.

In the third line, interesting results come from DBH and COMT enzymes. Although the metaanalyses of Taq1 and -1021 T/C in DBH gene and 158Val/Met in COMT gene have not identified susceptibility alleles, variants of these genes are associated with neuropsychological performance, peripheral levels, treatment response and symptomatology. 
Although the studies are often opposite or contradictory due to the heterogeneity of the disorder, SLC6A3, DRD4, MHPG, MAOA, NE, SLC6A2, DBH, COMT could represent, in this order, a hypothetical signature of a set of genetic and biochemical markers useful for ADHD diagnosis. In the absence of medications, peripheral levels of MAOA, DBH and also PEA were observed correlated with ADHD behaviour. Of this hypothetical signature, SLC6A3 10R, DRD4 7R, COMT val158met, MAOA were also associated to major depressive disorder (MDD), schizophrenia, schizophrenia/anxiety disorders/bipolar disorder and obsessive-compulsive disorder, respectively [60]. Moreover, peripheral levels of MHPG have been found associated to manic syndrome in bipolar disorder [61], to microstructural changes within the cerebellum in first-episode schizophrenia [62] and to melancholic MDD, even though without correlation with duration/severity of depressive symptoms [63]. However, these findings, if they are lacking specificity, on the other hand, suggest the common biological mechanisms linked to dopaminergic and noradrenergic systems shareable with different psychiatric disorders, as recently supported [60].

In relation to the meta-analyses on the peripheral alterations of a biomarker after treatment, the results located, for the first time, the NE metabolite MHPG as the main molecule whose urinary levels are influenced by the d-AMP treatment. This association was significant also after Bonferroni correction. The other molecules such as DA, DOPAC, HVA, NE, NM, VMA are not modified by the stimulants treatment and they are not correlated with behavioural modifications after different drugs. Although there are not enough studies, suggestive results have been obtained for PEA molecule, even though no evidence of correlation between peripheral levels and behavioural features was observed after d-AMP treatment (see Table 1). Moreover, we found a slight evidence of publication bias for MHPG and a significant heterogeneity of effect sizes across studies for all biomarkers that significantly differentiated treated ADHD patients from untreated.

Considering the present data along with the recent meta-analysis [12], MHPG could be a potential biomarker for ADHD diagnosis and a potential predictor of treatment response. Indeed, when we compared urinary levels of MHPG among patients with ADHD and control subjects, the meta-analysis [12] indicated a significant decrease in patients. Similarly, the administration of d-AMP significantly reduced the urinary levels of MHPG (present data). This, along with the well-reported correlation between decrease in MHPG and behavioural improvements after d-AMP treatment [45, 49, 54, 50, 51, 53] (see Table 1), focuses attention on MHPG as a potential mediator of stimulant drug response, in addition to a useful biological marker for diagnostic assessment. More interestingly, urinary MHPG levels are decreased after stimulants administration only in the responders patients, indicating that MHPG could be a useful predictor of the stimulants response.

The metabolite MHPG is a major product of NE breakdown. A significant fraction of urinary MHPG (as much as $30-50 \%$ ) comes from the metabolism of NE in the CNS in man. This is supported by some evidence that destruction of NE terminals in the CNS of animals resulted in decreased urinary levels of MHPG. Moreover, MHPG excretion in urine has been shown to vary in response to changes in sympathetic activity or stressful situations. According to some authors [51], reduced MHPG may be considered linked to decreased activity of MAO enzyme. 
Indeed, the results of the meta-analysis [12] demonstrated lower MAO and MHPG and higher NE concentrations in patients with ADHD, supporting the current hypothesis that reduced MAO activity impairs the degradation of NE and leads to lower levels of MHPG in patients with ADHD.

Our results on the treatment contribute also to clarify the mechanism of action of d-AMP on the MHPG levels. In agreement with some authors [51], we hypothesized that d-AMP, by inhibiting the re-uptake of NE by the pre-synaptic nerve terminal and the intraneuronal MAO, tends to decrease MHPG. A similar mechanism could be hypothesized also for MPH because, although the results are negative ( $p=0.06$ see Figure 5$)$, three studies $[52,48,44]$ confirmed lower levels of MHPG in treated patients with ADHD. This supports also the evidence that d$\mathrm{AMP}$ and MPH are remarkably similar in their clinical effects.

Few studies have been conducted on other medications such as pycnogenol, pemoline and MAOIs, which make it difficult to interpret the lack of statistical significance for these medications. To date, the current evidence is insufficient to support the use of pycnogenol for the treatment of any chronic disorder including ADHD and well-designed, adequately powered trials are needed to establish the value of this treatment [64]. Concerning pemoline, because 15 cases of acute fulminant hepatic failure with this treatment have been reported, its use has been relegated to only rare circumstances $[65,66]$. Moreover, MAOIs are a group of antidepressants that can treat ADHD with some benefit, but are rarely used because they have significant and sometimes dangerous side effects and can dangerously interact with foods and other medications. Finally, one study [42] reported the biochemical monoamine determinations in relation to aspartame treatment. They demonstrated that aspartame at greater than 10 times usual consumption has no effect on the cognitive and behavioural status of children with ADHD. In addition, aspartame does not appear to affect the urinary excretion rates of monoamines and metabolites [42].

These data in general suffer of one important limitation that is specificity/sensitivity. All papers reported in the review and in the different meta-analyses are lacking this information. It is also important to highlight that most of these studies were conducted around '80s, '90s. Moreover, the data related to meta-analyses analyzing the effects of the treatment on a biomarker have some further limitations. In particular, (a) we found significant heterogeneity in effect size across the studies for all biomarkers analyzed. This could be due to several issues: (1) no homogeneity in the study designs because some studies used a placebo or baseline approach; (2) different concentrations of drugs used in the several studies; (3) different treatment time duration (from 1 week to 15 weeks); (4) methods to value the treatment response; (5) methodological procedures: repeated measurements on each child were not performed in all studies; over time, several methods for measuring catecholamines were used [67] (studies include a wide temporal range: urine levels of DA: from 1978 to 2007; HVA: from 1971 to 1994; NE: from 1971 to 2007; VMA: from 1971 to 1988); (6) many of the studies were generated by the same group (Shekim and Zametkin); (7) low significant effect sizes [68]. (b) The presence of publication bias for MHPG. This was due by the paper from Zametkin et al. [45]. However, when this paper was eliminated, the Egger test was not significant ( $p=0.21$ data not shown) 
and the meta-analysis for this metabolite was still significant $(d=0.62, Z=6.27, p<0.00001$ with less heterogeneity $p=0.09, I^{2}=34 \%$, data not shown).

Future research should be focused on the replication of these findings, to assess their specificity for ADHD, and to quantify the degree to which they are sufficiently precise to be useful in clinical settings. Thus more work is needed to determine whether the statistical significance of our findings translate into diagnostic utility. Moreover, future studies will have to take into account the deep integration of "omics" sciences such as the "pharmacogenomics", "phenomics", "epigenomic", "proteomics", “transcriptomic", "metabolomics". To date, the use of highthroughput computational methods such as learning machinery permits to integrate the complex network of genes (DNA, RNA), proteins and biochemical interactions along with clinical and endophenotype profiling including therapeutic response to identify a set of biomarkers useful for the diagnostic assessment and for the personalization of therapies.

\section{Conclusion}

Currently, no biomarkers for ADHD have achieved the status of clinical utility as a diagnostic tool. This chapter supports evidence for a role of some dopaminergic and noradrenergic molecules, their metabolites and metabolism enzymes such as SLC6A3, DRD4, MHPG, MAOA, $\mathrm{NE}, \mathrm{SLC} 6 \mathrm{A2}$, DBH, COMT that could represent, in this order, a hypothetical signature of a set of genetic and biochemical markers useful for ADHD diagnosis. Moreover, this chapter demonstrates, for the first time, with a meta-analytic method, that d-AMP influences urinary MHPG levels and that, if it is tested, MHPG could be a useful predictor of response to stimulants. Although further studies are needed mainly in relation to specificity and sensitivity, we speculate that MHPG could be the best potential candidate as biomarker for ADHD.

\section{Author details}

Catia Scassellati ${ }^{*}$ and Cristian Bonvicini

*Address all correspondence to: cscassellati@fatebenefratelli.eu

Genetics Unit, IRCCS - Centre Saint John of God, Fatebenefratelli, Brescia, Italy

\section{References}

[1] Polanczyk G, de Lima MS, Horta BL, Biederman J, Rohde LA. The worldwide prevalence of ADHD: a systematic review and metaregression analysis. Am J Psychiatr 2007;164(6):942-8. 
[2] Willcutt EG. The prevalence of DSM-IV attention-deficit/hyperactivity disorder: a meta-analytic review. Neurotherapeutics 2012;9(3):490-9.

[3] Polanczyk GV, Willcutt EG, Salum GA, Kieling C, Rohde LA. ADHD prevalence estimates across three decades: an updated systematic review and meta-regression analysis. Int J Epidemiol 2014;43(2):434-42.

[4] Simon V, Czobor P, Balint S, Meszaros A, Bitter I. Prevalence and correlates of adult attention-deficit hyperactivity disorder: metaanalysis. Brit J Psychiatr 2009;194(3): 204-11.

[5] Ramos-Quiroga JA, Nasillo V, Fernández-Aranda F, Casas M. Addressing the lack of studies in attention-deficit/hyperactivity disorder in adults. Exp Rev Neurotherapeutics 2014;14(5):553-67.

[6] Thapar A, Cooper M, Eyre O, Langley K. What have we learnt about the causes of ADHD? J Child Psychol Psychiatr 2013;54(1):3-16.

[7] Faraone SV, Perlis RH, Doyle AE, Smoller JW, Goralnick JJ, Holmgren MA, Sklar P. Molecular genetics of attention-deficit/hyperactivity disorder. Biol Psychiatr 2005;57(11):1313-23.

[8] Li Z, Chang SH, Zhang LY, Gao L, Wang J. Molecular genetic studies of ADHD and its candidate genes: a review. Psychiatr Res 2014;219(1):10-24.

[9] Akutagava-Martins GC, Salatino-Oliveira A, Kieling CC, Rohde LA, Hutz MH. Genetics of attention-deficit/hyperactivity disorder: current findings and future directions. Exp Rev Neurotherapeutics 2013;13(4):435-45.

[10] Yang L, Neale BM, Liu L, Lee SH, Wray NR, Ji N, et al. Psychiatric GWAS Consortium: ADHD Subgroup. Polygenic transmission and complex neuro developmental network for attention deficit hyperactivity disorder: genome-wide association study of both common and rare variants. Am J Med Genet B, Neuropsychiatr Genet 2013;162B(5):419-30.

[11] Gizer IR, Ficks C, Waldman ID. Candidate gene studies of ADHD: a metaanalytic review. Human Genetics 2009;126(1):51-90.

[12] Scassellati C, Bonvicini C, Faraone SV, Gennarelli M. Biomarkers and attention-deficit/hyperactivity disorder: a systematic review and meta-analyses. J Am Acad Child Adolesc Psychiatr 2012;51(10):1003-19.

[13] Lange KW, Reichl S, Lange KM, Tucha L, Tucha O. The history of attention deficit hyperactivity disorder. Attention Deficit Hyperactivity Disorders 2010;2(4):241-55.

[14] Insel T. Director's Blog: transforming diagnosis. 2013 http://www.nimh.nih.gov/ about/director/2013/transforming-diagnosis.shtml

[15] Kornfield R, Watson S, Higashi AS, Conti RM, Dusetzina SB, Garfield CF, Dorsey ER, Huskamp HA, Alexander GC. Effects of FDA advisories on the pharmacologic treat- 
ment of ADHD, 2004-2008. Psychiatric Services (Washington, D.C.) 2013;64(4):33946.

[16] Findling RL. Evolution of the treatment of attention-deficit/hyperactivity disorder in children: a review. Clin Therapeut 2008;30(5):942-57.

[17] Spencer T, Biederman J, Wilens T, Harding M, O'Donnell D, Griffin S. Pharmacotherapy of attention-deficit hyperactivity disorder across the life cycle. J Am Acad Child Adoles Psychiatr 1996;35(4):409-32.

[18] Swanson J, Baler RD, Volkow ND. Understanding the effects of stimulant medications on cognition in individuals with attention-deficit hyperactivity disorder: a decade of progress. Neuropsychopharmacology 2011;36(1):207-26.

[19] Faraone SV, Buitelaar J. Comparing the efficacy of stimulants for ADHD in children and adolescents using meta-analysis. Eur Child Adoles Psychiatr 2010;19(4):353-64.

[20] Faraone SV. Using meta-analysis to compare the efficacy of medications for attention-deficit/hyperactivity disorder in youths. P \& T: J Formul Manage 2009;34(12): 678-94.

[21] Cheng JY, Chen RY, Ko JS, Ng EM. Efficacy and safety of atomoxetine for attentiondeficit/hyperactivity disorder in children and adolescents-meta-analysis and meta-regression analysis. Psychopharmacology (Berl) 2007;194(2):197-209.

[22] Hazell PL, Kohn MR, Dickson R, Walton RJ, Granger RE, Wyk GW. Core ADHD symptom improvement with atomoxetine versus methylphenidate: a direct comparison meta-analysis. J Attent Disorders 2011;15(8):674-83.

[23] Dvoráková M, Jezová D, Blazícek P, Trebatická J, Skodácek I, Suba J, Duracková Z. Urinary catecholamines in children with attention deficit hyperactivity disorder (ADHD): modulation by a polyphenolic extract from pine bark (pycnogenol). Nutrit Neurosci 2007;10(3-4):151-7.

[24] De Sousa A, Kalra G. Drug therapy of attention deficit hyperactivity disorder: current trends. Mens sana Monographs 2012;10(1):45-69.

[25] Biomarkers Definitions Working Group. Biomarkers and surrogate endpoints: preferred definitions and conceptual framework. Clin Pharmacol Therapeut 2001;69(3): 89-95.

[26] Schmidt HD, Shelton RC, Duman RS. Functional biomarkers of depression: diagnosis, treatment, and pathophysiology. Neuropsychopharmacol 2011;36(12):2375-94.

[27] Sokolowska I, Ngounou Wetie AG, Wormwood K, Thome J, Darie CC, Woods AG. The potential of biomarkers in psychiatry: focus on proteomics. J Neural Transmiss (Vienna, Austria: 1996) 2013;20.

[28] Singh I, Rose N. Biomarkers in psychiatry. Nature 2009;460(7252):202-7. 
[29] Genro JP, Kieling C, Rohde LA, Hutz MH. Attention-deficit/hyperactivity disorder and the dopaminergic hypotheses. Exp Rev Neurotherapeut 2010;10(4):587-601.

[30] Bidwell LC, Willcutt EG, McQueen MB, DeFries JC, Olson RK, Smith SD, Pennington BF. A family based association study of DRD4, DAT1, and 5HTT and continuous traits of attention-deficit hyperactivity disorder. Behavior Genet 2011;41(1):165-74.

[31] Horn A, Scheller C, du Plessis S, Arendt G, Nolting T, Joska J, Sopper S, Maschke M, Obermann M, Husstedt IW, Hain J, Maponga T, Riederer P, Koutsilieri E. Increases in CSF dopamine in HIV patients are due to the dopamine transporter 10/10-repeat allele which is more frequent in HIV-infected individuals. J Neural Transmiss (Vienna, Austria: 1996) 2013;120(10):1411-9.

[32] Cheon KA, Ryu YH, Kim JW, Cho DY. The homozygosity for 10-repeat allele at dopamine transporter gene and dopamine transporter density in Korean children with attention deficit hyperactivity disorder: relating to treatment response to methylphenidate. Eur Neuropsychopharmacol: J Eur College Neuropsychopharmacol 2005;15(1):95-101.

[33] Faraone SV, Bonvicini C, Scassellati C. Biomarkers in the diagnosis of ADHD--promising directions. Current Psychiatr Rep 2014;16(11):497; DOI 10.1007/ s11920-014-0497-1.

[34] Koutsilieri E, Riederer P, du Plessis S, Scheller C. A short review on the relation between the dopamine transporter 10/10-repeat allele and ADHD: implications for HIV infection. Attent Deficit Hyperactivity Disorders 2014;6(3):203-9.

[35] Wu J, Xiao HF, Sun HJ, Zou L, Zhu LQ. Role of dopamine receptors in ADHD: a systematic meta-analysis. Molecular Neurobiol 2012;45(3):605-20.

[36] Tovo-Rodrigues L, Rohde LA, Menezes AM, Polanczyk GV, Kieling C, Genro JP, Anselmi L, Hutz MH. DRD4 rare variants in attention-deficit/hyperactivity disorder (ADHD): further evidence from a birth cohort study. PLoS One 2013;8(12):e85164.

[37] Taurines R, Segura M, Schecklmann M, Albantakis L, Grünblatt E, Walitza S, Jans T, Lyttwin B, Haberhausen M, Theisen FM, Martin B, Briegel W, Thome J, Schwenck C, Romanos M, Gerlach M. Altered mRNA expression of monoaminergic candidate genes in the blood of children with attention deficit hyperactivity disorder and autism spectrum disorder. World J Biol Psychiatr: Off J World Fed Soc Biol Psychiatr 2011;12(Suppl 1):104-48.

[38] Wender PH, Epstein RS, Kopin IJ, Gordon EK. Urinary monoamine metabolites in children with minimal brain dysfunction. Am J Psychiatr 1971;127(10):1411-5.

[39] Lasky-Su J, Anney RJ, Neale BM, Franke B, Zhou K, Maller JB, Vasquez AA, Chen W, Asherson P, Buitelaar J, Banaschewski T, Ebstein R, Gill M, Miranda A, Mulas F, Oades RD, Roeyers H, Rothenberger A, Sergeant J, Sonuga-Barke E, Steinhausen HC, Taylor E, Daly M, Laird N, Lange C, Faraone SV. Genome-wide association scan of quantitative traits for attention deficit hyperactivity disorder identifies novel associa- 
tions and confirms candidate gene associations. Am J Med Genet B, Neuropsychiatr Genet 2008;147B(8):1345-54.

[40] Sun HJ, Yuan FF, Shen XM, Xiong GL, Wu J. Role of COMT in ADHD: a systematic meta-analysis. Molecular Neurobiol 2014;49(1):251-61.

[41] Egger M, Smith GD, Phillips AN. Meta-analysis: principles and procedures. Brit Med J 1997;315(7121):1533-7.

[42] Shaywitz BA, Sullivan CM, Anderson GM, Gillespie SM, Sullivan B, Shaywitz SE. Aspartame, behavior, and cognitive function in children with attention deficit disorder. Pediatrics 1994;93(1):70-5.

[43] Zametkin AJ, Linnoila M, Karoum F, Sallee R. Pemoline and urinary excretion of catecholamines and indoleamines in children with attention deficit disorder. Am J Psychiatr 1986;143(3):359-62.

[44] Zametkin AJ, Karoum F, Linnoila M, Rapoport JL, Brown GL, Chuang LW, Wyatt RJ. Stimulants, urinary catecholamines, and indoleamines in hyperactivity. A comparison of methylphenidate and dextroamphetamine. Arch Gen Psychiatr 1985;42(3):25155 a.

[45] Zametkin A, Rapoport JL, Murphy DL, Linnoila M, Karoum F, Potter WZ, Ismond D. Treatment of hyperactive children with monoamine oxidase inhibitors. II. Plasma and urinary monoamine findings after treatment. Arch Gen Psychiatr 1985;42(10): 969-73 b.

[46] Rapoport JL, Mikkelsen EJ, Ebert MH, Brown GL, Weise VK, Kopin IJ. Urinary catecholamines and amphetamine excretion in hyperactive and normal boys. J Nervous Mental Disease 1978;166(10):731-7.

[47] Elia J, Borcherding BG, Potter WZ, Mefford IN, Rapoport JL, Keysor CS. Stimulant drug treatment of hyperactivity: biochemical correlates. Clin Pharmacol Therapeut 1990;48(1):57-66.

[48] Zametkin AJ, Hamburger SD. The effect of methylphenidate on urinary catecholamine excretion in hyperactivity: a partial replication. Biol Psychiatr 1988;23(4):350-6.

[49] Shekim WO, Javaid J, Davis JM, Bylund DB. Urinary MHPG and HVA excretion in boys with attention deficit disorder and hyperactivity treated with d-amphetamine. Biol Psychiatr 1983;18(6):707-14.

[50] Brown GL, Ebert MH, Hunt RD, Rapoport JL. Urinary 3-methyoxy-4-hydroxyphenylglycol and homovanillic acid response to d-amphetamine in hyperactive children. Biol Psychiatr 1981;16(8):779-87.

[51] Shekim WO, Dekirmenjian H, Chapel JL, Javaid J, Davis JM. Norepinephrine metabolism and clinical response to dextroamphetamine in hyperactive boys. J Pediatr 1979;95(3):389-94a. 
[52] Shen YC, Wang YF. Urinary 3-methoxy-4-hydroxyphenylglycol sulfate excretion in seventy-three schoolchildren with minimal brain dysfunction syndrome. Biol Psychiatr 1984;19(6):861-70.

[53] Shekim WO, Dekirmenjian H, Chapel JL. Urinary MHPG excretion in minimal brain dysfunction and its modification by d-amphetamine. Am J Psychiatr 1979;136(5):667$71 b$.

[54] Shekim WO, Javaid J, Dekirmenjian H, Chapel JL, Davis JM. Effects of d-amphetamine on urinary metabolites of dopamine and norepinephrine in hyperactive boys. Am J Psychiatr 1982;139(4):485-8.

[55] Shekim WO, Dekirmenjian H, Chapel JL. Urinary catecholamine metabolites in hyperkinetic boys treated with d-amphetamine. Am J Psychiatr 1977;134(11):1276-9.

[56] Shekim WO, Dekirmenjian H, Chapel JL. Urinary MHPG excretion in the hyperactive child syndrome and the effects of dextroamphetamine [proceedings]. Psychopharmacol Bull 1978;14(2):42-4.

[57] Kusaga A, Yamashita Y, Koeda T, Hiratani M, Kaneko M, Yamada S, Matsuishi T. Increased urine phenylethylamine after methylphenidate treatment in children with ADHD. Ann Neurol 2002;52(3):372-4.

[58] Zametkin AJ, Brown GL, Karoum F, Rapoport JL, Langer DH, Chuang LW, Wyatt RJ. Urinary phenylethylamine response to d-amphetamine in 12 boys with attention deficit disorder. Am J Psychiatr 1984;141(9):1055-8.

[59] Franke B, Hoogman M, Arias Vasquez A, Heister JG, Savelkoul PJ, Naber M, Scheffer H, Kiemeney LA, Kan CC, Kooij JJ, Buitelaar JK. Association of the dopamine transporter (SLC6A3/DAT1) gene 9-6 haplotype with adult ADHD. Am J Med GenetB, Neuropsychiatr Genet 2008;147B(8):1576-9.

[60] Gatt JM, Burton KL, Williams LM, Schofield PR. Specific and common genes implicated across major mental disorders: a review of meta-analysis studies. J Psychiatr Res 2015;60:1-13.

[61] Kurita M, Nishino S, Numata Y, Okubo Y, Sato T. The noradrenaline metabolite MHPG is a candidate biomarker from the manic to the remission state in bipolar disorder I: a clinical naturalistic study. PLoS One 2014;27(6):e100634.

[62] Nishimura J, Kakeda S, Abe O, Yoshimura R, Watanabe K, Goto N, Hori H, Sato T, Takao H, Kabasawa H, Nakamura J, Korogi Y. Plasma levels of 3-methoxy-4-hydroxyphenylglycol are associated with microstructural changes within the cerebellum in the early stage of first-episode schizophrenia: a longitudinal VBM study. Neuropsychiatr Disease Treat 2014;10:2315-23.

[63] Cubała WJ, Landowski J, Wielgomas B, Czarnowski W. Low baseline salivary 3-methoxy-4-hydroxyphenylglycol (MHPG) in drug-naïve patients with short-illness-duration first episode major depressive disorder. J Affective Disorders 2014;161:4-7. 
[64] Schoonees A, Visser J, Musekiwa A, Volmink J. Pycnogenol(®) for the treatment of chronic disorders. Cochrane Database Syst Rev 2012;15;2:CD008294; doi: 10.1002/14651858.

[65] Markowitz JS, Patrick KS. Pharmacokinetic and pharmacodynamic drug interactions in the treatment of attention-deficit hyperactivity disorder. Clin Pharmacokinet 2001;40(10):753-72.

[66] Safer DJ, Zito JM, Gardner JE. Pemoline hepatotoxicity and postmarketing surveillance. J Am Acad Child Adoles Psychiatr 2001;40(6):622-9.

[67] Marc DT, Ailts JW, Campeau DC, Bull MJ, Olson KL. Neurotransmitters excreted in the urine as biomarkers of nervous system activity: validity and clinical applicability. Neurosci Biobehavioral Rev 2011;35(3):635-44.

[68] Zakzanis KK. Brain is related to behavior $(\mathrm{p}<.05)$. J Clin Experiment Neuropsychol 1998;20(3):419-27. 
